\title{
Magnesium pemoline: Effects on active and passive avoidance conditioning in mice
}

\author{
CYNTHIA WIMER, SUSAN DONNER, AND DAVID MARTIN, \\ THE JACKSON LABORATORY, Bar Harbor, Me. 04609
}

Mice administered magnesium pemoline in doses having a stimulant or non-stimulant effect on activity learned to actively avoid shock better than controls, but were no different from controls in passive avoidance conditioning. The results implied that any facilitation produced by pemoline could not clearly be attributed to a single mechanism. It was suggested that a dual effect of activity stimulation and increased reactivity to shock provides the most plausible explanation for the findings.

The hypothesis that magnesium pemoline, a central nervous system stimulant, exerts a facilitating effect on the learning of a conditioned avoidance response by acting directly on a basic learning mechanism has been supported by the results of Plotnikoff $(1966 ; 1967)$ and Kulkarni (1967). These experiments have in common the fact that the tasks involved require an active response, that the superior animal is in general the more active animal. Lubar et al (1967) cast some doubt on the above hypothesis by showing that animals learning the Hebb-Williams maze problems under the drug were faster than controls, but that there was no clear reduction of errors. Frey \& Polidora (1967) have suggested that a more economical explanation is that pemoline exerts its major effect through the stimulation of motor activity and thus reduction of freezing, or through increased responsivity to shock. This interpretation has been supported by their own experiments as well as those of Beach \& Kimble (1967), Filby et al (1967), and Chase \& Rescorla (1968).

If activity stimulation is the major mechanism for pemoline's effect on active avoidance, the conditioning of a passive avoidance response should be disrupted, an implication supported by the. findings of Gurowitz et al (1967). In the present experiment, we attempted to directly compare active and passive avoidance conditioning by defining an activity response that occurred about half the time in the animal's normal repertoire, and then experimentally increasing or decreasing its frequency of occurrence by administering shock. The effects of magnesium pemoline were compared with those of d-amphetamine sulphate, a central nervous sytem stimulant that has effects on general activity (Wimer \& Fuller, 1965) but presumably not on the learning mechanism per se.

Subjects. ${ }^{2}$ The Ss were 100 six-week-old male mice of the strain DBA/2J, with an average weight of $20 \mathrm{~g}$. They were maintained on ad lib food and water throughout the experiment.
Apparatus. The apparatus for behavioral testing was a $7 \times 7 \times 7$-in. translucent Plexiglas box with a grid floor consisting of 3/32-in. stainless steel rods separated by about $1 / 4 \mathrm{in}$. between the centers. Foot shock of $.1 \mathrm{~mA}$ through the floor was controlled by a microswitch. Duration of shock was recorded on a Meylan timer.

Procedure. An active response was defined as any movement of the feet, including rearing. All other behavior, such as freezing, sniffing, grooming, etc., was called passive. During the 5-min testing periods, the microswitch was depressed during all active responses and duration of activity was recorded. For passive avoidance conditioning depression of the microswitch turned on the shock; for active avoidance shock was turned on by release of the microswitch, and was off while it was depressed.

Stimulant and non-stimulant dose levels, as defined by effect on spontaneous motor activity during a 5 -min period in the test box, were established for each drug. The dosages found to produce parallel effects on activity (see Fig. 1a and 1b, Trial 2) were 12.50 and $25.00 \mathrm{mg} / \mathrm{kg}$ of magnesium pemoline ${ }^{3}$ and 1.50 and $6.25 \mathrm{mg} / \mathrm{kg}$ of d-amphetamine sulphate. The placebo was a $10 \%$ solution of gum acacia, also used as the vehicle for both drugs, which were administered orally via a polyethylene tube attached to a Yale tuberculin syringe. To control for the different time courses of the two drugs, amphetamine was administered $30 \mathrm{~min}$ and pemoline $75 \mathrm{~min}$ prior to testing. Forty-eight $h$ elapsed between each 5 -min test trial.

On the first test trial, activity without shock or drug was measured in the test box for a 5-min period. On the basis of this measure, the animals were divided into five drug groups equated for basic activity level. On the second trial, activity under the drug was measured, and each of the drug groups was divided into two equated sub-groups of 10 mice each, one of which was assigned to the active, and the other to the passive avoidance conditioning tasks. During the next four test trials the animals were trained on their respective tasks under drug administration. The $\mathrm{E}$ carrying out the behavioral testing did not know the drug condition of any $S$, nor did the $E$ injecting the drugs know any S's behavioral scores.

Results. Figure $1 a$ and $b$ show the trial-to-trial changes in activity for all groups. Clearly, for both stimulant and nonstimulant doses, both drugs had a considerably greater effect on the learning of the active task than on the passive. The group means for Trials 3 to 6 were compared in four separate analyses of variance. For the active task, the stimulant doses of both drugs significantly facilitated learning $(F=19.17 ; \mathrm{df}=2 / 25 ; \mathrm{p}<.01)$. Although amphetamine produced consistently higher learning scores than did pemoline, the difference did not reach the .05 level of significance $(F=3.82 ; \mathrm{df}=1 / 25 ; .05<\mathrm{p}<.10)$. The nonstimulant doses of both drugs also resulted in a significant facilitation of the active task $(F=7.78 ; \mathrm{df}=2 / 27 ; \mathrm{p}<.01)$. In this analysis there was also a significant interaction between drugs and

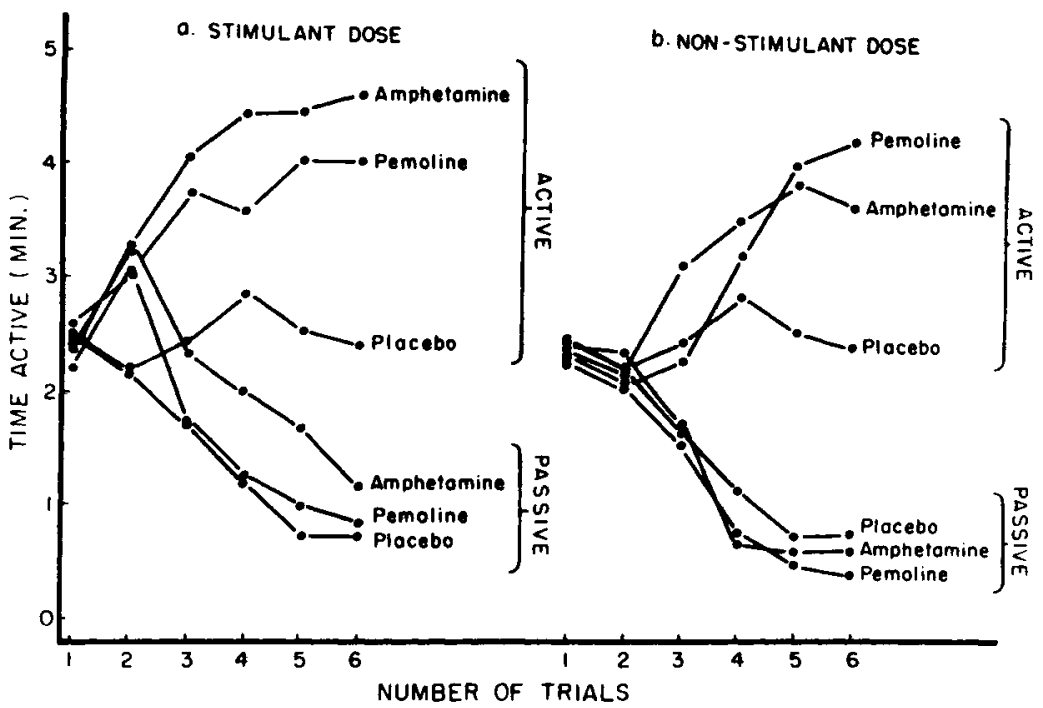

Fig. 1. Minutes of activity of all drug groups for active and passive avoidance tasks. Trials 1 and 2 measured activity without shock: without drug on Trial 1, and with drug on Trial 2. Trials 3.6 are conditioning sessions. $N=10$ per group. 
trials $(F=4.75 ; \mathrm{df}=6 / 81 ; \mathrm{p}<.01)$, suggesting a comparatively delayed effect for pemoline.

In the passive task there was more consistent improvement over trials, and this effect was significant for both stimulant $(F=19.10$; $\mathrm{df}=3 / 75 ; \mathrm{p}<.01)$ and non-stimulant $(\mathrm{F}=38.05 ; \mathrm{df}=3 / 81$; $\mathrm{p}<.01)$ doses. Groups receiving stimulant doses of drugs did not learn as well as those receiving a placebo. The main effect for drugs was significant $(F=4.53 ; \mathrm{df}=2 / 25 ; \mathrm{p}<.05)$ and $\mathrm{Ss}$ receiving pemoline learned significantly more rapidly than those receiving amphetamine $(\mathrm{F}=5.88 ; \mathrm{df}=1 / 25 ; \mathrm{p}<.05)$. Although it appears that non-stimulant doses may have some facilitating effect on the passive task, the effect is not significant $(F=1.46$; $\mathrm{df}=2 / 27 ; p \cong .25$ ).

Discussion. The major effect of the administration of both magnesium pemoline and d-amphetamine was a facilitation of learning of an active avoidance response, a response in which the placebo group showed little or no improvement in the course of the learning trials. The results cannot, however, be considered as conclusive support for the hypothesis that pemoline exerts its major effect by directly stimulating motor activity, for two reasons: first, there was little difference between the stimulant and non-stimulant dose (defined by effect on basal activity) in their facilitation of performance; and second, the passive task was learned as well by the pemoline animals as by the placebo group, whereas it would be expected that an agent that increased activity would interfere with the learning of a passive response, if activity stimulation were its only effect. Amphetamine fits this picture better than pemoline: the stimulant dose is superior to the non-stimulant for the active task and inferior for the passive.

The findings, then, are not in complete agreement with those of previous studies, for active avoidance was facilitated by magnesium pemoline while passive avoidance was neither improved nor disrupted. If, however, pemoline increases responsivity to shock as well as stimulating activity, we might expect the two effects to be additive in active avoidance, thus producing considerable facilitation, and perhaps to cancel each other in passive avoidance, thus having no apparent effect. Supporting this possibility is the fact that the pemoline dose that had no apparent effect on basal activity level did produce some facilitation of both active and passive avoidance.

It should be pointed out that a dual mechanism involving activity stimulation and direct effects on the learning mechanism would equally well account for these results, for the experiment does not permit the separation of learning and performance effects which would presumably distinguish between increased responsivity and improved learning. Previous results, however, have provided more support for the responsivity hypothesis. Thus, the most plausible explanation of the present results is that magnesium pemoline exerts its facilitating effect through the dual mechanism of activity stimulation and increased reactivity to shock.

\section{REFERENCES}

BEACH, G., \& KIMBLE, D. P. Activity and responsivity in rats after magnesium pemoline injections. Science, 1967, 155, 698-701.

CHASE, T. C., \& RESCORLA, R. A. The effect of magnesium pemoline on learning an active avoidance-passive avoidance discrimination. Psychon. Sci, 1968, 10, 87-88.

FILBY, Y., SZARA, S., \& SALZMAN, B. Magnesium pemoline: Effect on acquisition and retention of discriminated avoidance behavior. Psychon. Sci, 1967, 9, 131-132.

FREY, P. W., \& POLIDORA, V. J. Magnesium pemoline: Effect on avoidance conditioning in rats. Science, 1967, 155, 1281-1282.

GUROWITZ, E. M., LUBAR, J. F., AIN, B. R., \& GROSS, D. A. Disruption of passive-avoidance learning by magnesium pemoline. Psychon. Sci, 1967, 8, 19-20.

KULKARNI, A. S. Magnesium pemoline: Facilitation of instrumental avoidance learning. Psychon. Sci., 1967, 9, 39-40.

LUBAR, J. F., BOITANO, J. J., GUROWITZ, E. M., \& AIN, B. R. Enhancement of performance in the Hebb-Williams maze by magnesium pemoline. Psychon. Sci, 1967, 7, 381-382.

PLOTNIKOFF, N. Magnesium pemoline: Enhancement of learning and memory of a conditioned avoidance response. Science, 1966, 151, 703-704.

PLOTNIKOFF, N. Pemoline and magnesium hydroxide: Memory consolidation following acquisition trials. Psychon. Sci, 1967, 9, 141-142.

WIMER, R. E., \& FULLER, J. L. The effects of d-amphetamine sulphate on three exploratory behaviors. Can. J. Psychol., 1965, 19, 94-103.

\section{NOTES}

1. This investigation was supported in part by Public Health Service Research Grant HD 02491 from the National Institute of Child Health and Human Development, and in part by Training Grant GW-682 from the National Science Foundation.

2. The principles of laboratory animal care as promulgated by the American Psychological Association are observed in this laboratory.

3. Cylert; Abbott 30400. We thank Abbott Laboratories for providing magnesium pemoline, and Dr. N. Plotnikoff for his advice on dose levels. 